\title{
COOPERAÇÃO, COMPETIÇÃO E COOPETIÇÃO NAS RELAÇÕES ENTRE PEQUENOS FEIRANTES DE UM AGLOMERADO DE VAREJO EM ARACAJU-SE
}

\author{
COOPERATION, COMPETITION AND COOPERATION IN RELATIONS \\ WITH SMALL FAIRANTS IN ARACAJU-SE RETAIL AGREEMENT
}

\section{Everiline de Souza Bispo}

Graduada em Administração pela Universidade Federal de Sergipe (São Cristóvão/Brasil).

E-mail: everiline.bispo@gmail.com

\section{Rosangela Sarmento Silva}

Doutora em Administração pela Universidade Municipal de São Caetano do Sul (São Paulo/Brasil).

Professora Dr. ${ }^{a}$ do Departamento de Administração e Professora Colaboradora do Mestrado em Administração na

Universidade Federal de Sergipe (São Cristóvão/Brasil).

E-mail: rosangelasarmento13@gmail.com

\section{Juliana Moreira dos Santos}

Graduada em Administração pela Universidade Federal do Sul e Sudeste do Pará (Marabá/Brasil). Conselheira fiscal da Empresa Junior de Administração da Universidade Federal do Sul e Sudeste do Pará (Marabá/Brasil).

E-mail: julianamoreirasanto@gmail.com

\section{Esdras Antunes do Nascimento}

Mestrando em Administração pela Universidade Federal de Sergipe (São Cristóvão/Brasil).

Analista Universitário na Universidade Estadual do Sudoeste da Bahia (Vitória da Conquista/Brasil).

E-mail: eanascimento7@gmail.com 


\section{RESUMO}

Esta pesquisa teve como objetivo central identificar os fatores formadores da cooperação, competição e coopetição provenientes dos relacionamentos existentes entre pequenos feirantes do aglomerado alimentício do Mercado Municipal Maria Virgínia Leite Franco, considerado um cluster planejado localizado na cidade de Aracaju-SE. Para isso, foi desenvolvido um estudo descritivo de natureza quantitativa por meio da Análise Fatorial Exploratória (AFE). O instrumento foi aplicado com 120 lojistas pertencentes ao cluster. Como resultado, no construto cooperação/colaboração foram identificados dois fatores: Ações Conjuntas (AC) e Troca de Informações (TI). Quanto ao construto competição, foram identificados três fatores: Concorrência (CONC), Comportamento Oportunista (CO) e Competitividade do Aglomerado (CA). Por fim, no construto coopetição identificaram-se quatro fatores, a saber: Localização (LOC), Desenvolvimento da empresa (DE), Colaboração (COL) e Relacionamentos Interorganizacionais (RIOS). Conclui-se que a causalidade dos relacionamentos cooperativos, competitivos e coopetitivos são provenientes de uma ação humana, para manterem-se no mercado, e não uma estratégica planejada.

Palavras-chave: Aglomerações varejistas. Clusters. Coopetição.

\section{ABSTRACT}

The main objective of this research was to identify the factors that make up the cooperation, competition and coopetition arising from the relationships between small fairants stalls of the Maria Virgínia Leite Franco Municipal Market, considered a planned cluster located in the city of Aracaju-SE. For this, a descriptive study of quantitative nature was developed through Exploratory Factor Analysis (EFA). The instrument was applied at 120 tenants belonging to the cluster. As a result, in the cooperation construct, two factors were identified: Joint Actions (CA) and Information Exchange (IT). Regarding the competition construct, three factors were identified: Competition (CONC), Opportunistic Behavior (CO) and Cluster Competitiveness (CA). Finally, in the coopetition construct, four factors were identified, namely: Location (LOC), Company Development (DE), Collaboration (COL) and Interorganizational Relations (RIOS). It is concluded that the causality of cooperative, competitive and coopetitive relationships comes from a human action, to remain in the market and not planned strategic.

Keywords: Retail agglomerations. Clusters. Coopetition. 


\section{INTRODUÇÃO}

Durante boa parte do século XX, os principais alicerces do capitalismo gerencial foram a estabilidade, a imutabilidade e o equilíbrio (BALESTRIN; VERSCHOORE, 2008; BALESTRIN; VERSCHOORE; REYES JÚNIOR, 2010; FERREIRA; STOROPOLI; SERRA, 2014; KLEIN; ALVES; PEREIRA, 2015). No entanto, as mudanças socioeconômicas ocorridas a partir dos anos 1970, com destaque para o período pós 1990, alteraram o capitalismo, que agora possuía mercados globalizados, velocidade nos avanços tecnológicos e facilidade na troca de informações (BALESTRIN; VERSCHOORE, 2008; BALESTRIN; VERSCHOORE, 2016). Essas mudanças no ambiente concorrencial ocasionaram alterações também nas relações interfirmas, surgindo assim a cooperação (SILVA, 2016; PANDA, 2017), que se baseia na ideia que as empresas podem aprimorar seu desempenho agregando recursos complementares, habilidades e capacidades, buscando explorar benefícios mútuos (PADULA; DAGNINO, 2007; SILVA, 2016).

Com as adequações internas nas organizações decorrentes das novas parcerias cooperativas, surge a coopetição, onde as interdependências entre as empresas podem gerar, de fato, interesses convergentes e divergentes simultaneamente (PADULA; DAGNINO, 2007; SILVA, 2016; PANDA, 2017). A literatura de administração enfatiza a coopetição como um assunto importante, pois esta é entendida como colaboração entre concorrentes, ou seja, explica simultaneidade de cooperação e concorrência, onde as empresas complementam-se entre si, reunindo recursos e capacidades para obter uma vantagem competitiva (PANDA, 2017). Importante elencar que a coopetição é um assunto discutido na perspectiva da teoria dos jogos, alianças organizacionais, economia de custos de transação, visão baseada em recursos da empresa, redes e competições, sendo que estes estudos concentraram-se, particularmente, em seis temas, a saber: benefício mútuo, simultâneo, complexidade, variabilidade, gerenciamento de desafios e reformulação da indústria (CZAKON et al., 2014).

A literatura é desprovida de estudos sobre coopetição no nivel da rede e da firma (CZAKON et al., 2014; PANDA 2017), sendo por um lado não haver investigações suficientes sobre a evolução e existência de coopetição e, por outro, há menos aprofundamento sobre o equilíbrio da cooperação e da concorrência na dinâmica da coopetição, apontados no contexto brasileiro, apenas a pesquisa de Silva (2016). Embora as pesquisas tenham se centrado nos lados dominantes da coopetição de acordos entre empresas, isto é, relações dominadas pela cooperação, concorrência dominada pelas relações iguais (CZAKON et al., 2014), as causalidades desses relacionamentos permanecem inexploradas, principalmente no âmbito das pequenas empresas, fato este motivador desse estudo, uma vez que a coopetição é mais uma ação humana do que estratégica, ainda mais quando se tratam de pequenos negócios, que não são providos de todos os recursos necessários para se manterem no mercado (PANDA, 2017). 
Face ao exposto, a presente pesquisa, tem como objetivo identificar os fatores formadores da cooperação, competição e coopetição existentes entre pequenos feirantes do aglomerado alimentício do Mercado Municipal Maria Virgínia Leite Franco, considerado um cluster planejado na cidade de AracajuSE, tendo como base os estudos de Silva (2016). Desse modo, espera-se que esta pesquisa possibilite uma contribuição significativa para o crescimento do entendimento da coopetição em outros formatos organizacionais.

Para atender ao objetivo proposto, utilizou-se o método quantitativo de Análise Fatorial Exploratória (AFE), uma vez que não se conhecia antecipadamente o vínculo de dependência entre as variáveis e nem se os fatores possuíam uma estrutura de relação ou se essa estrutura poderia ser elucidada (CORRAR; PAULO; DIAS FILHO, 2009, p. 74). Os dados da pesquisa foram obtidos por meio do procedimento do tipo survey, intermediado com um questionário aplicado pessoalmente pelos pesquisadores com 120 feirantes, empregando uma escala bipolar de zero a dez para respostas de cada uma das 58 perguntas. A representação escalar considera zero igual à discordância total e 10 igual à concordância total. 0 instrumento de pesquisa utilizado é uma ferramenta validada por Silva (2016), composta pelos indicadores dos construtos competição, cooperação e coopetição, com adaptações decorrentes das mudanças quanto ao objeto e cenário da pesquisa.

A fim de evidenciar a pesquisa realizada, este artigo tem sua composição distribuída em quatro seções, além desta introdutória. Nesse sentido, na segunda seção apresenta-se o referencial teórico, que aborda a temática de clusters e aglomerações varejistas, além das teorias competitiva, cooperativa e coopetitiva. Na terceira seção, descreve-se a metodologia empregada na pesquisa, revelando, também, o fator limitante da pesquisa. Na quarta seção, constam a análise dos resultados e as considerações teóricas. E, por fim, na quinta seção, anunciam-se as considerações finais, juntamente com as sugestões para estudos futuros.

\section{REFERENCIAL TEÓRICO}

Este capítulo trata do referencial teórico para fundamentar a pesquisa. Para isso, são discutidas a teoria de cluster e aglomerações varejistas, bem como a teoria competitiva, cooperativa e coopetitiva.

\subsection{CLUSTERS E AGLOMERAÇÕES VAREJISTAS}

A terminologia Cluster é definida por Michael Porter em seu artigo "Cluster and the new economics of competition" como "concentrações geográficas de companhias e instituições interconectadas em um mercado específico" (PORTER, 1998, p. 78). No entanto, foi com Marshall e seus estudos acerca da indústria 
inglesa do final do século XIX que se manifestaram as primeiras teorias relacionadas com aglomerações, referenciando-se sobre o tema na obra "Princípios de Economia", onde definia as aglomerações industriais como "indústrias concentradas em certas localidades" (MARSHALL, 1996, p. 318).

ParaPorter (1989), o advento daglobalização eliminou os argumentos tradicionais quesubstanciavam os aglomerados, como a limitação das fontes de abastecimento e mercados compradores, ele entende que os clusters devem envolver não só custos como também diferenciação, melhoria contínua e inovação, além de valorizar a velocidade de aprendizado e o uso da informação dentro do próprio cluster.

Autores como Nalebuff e Brandenburger (1996) perceberam que além da competição, há também vantagens advindas das relações colaborativas entre organizações. Dentre essas vantagens é possível citar parcerias para desenvolvimento de tecnologias, partilha de maquinário, bem como boas práticas colaborativas entre parceiros (BALESTRIN; VERSCHOORE, 2008).

Originalmente imaginava-se que empresas isoladas se destacavam por se manterem longe da concorrência, e por esse motivo não disputarem mercado e nem receita (TELLES, 2008). No entanto, observou-se que os aglomerados expandem as capacidades competitivas de quem os compõem, "tornando-os mais aptos a vencer seus concorrentes no confronto pela preferência dos compradores" (ZACCARELLI et al., 2008, p. 70).

\subsection{A TEORIA COMPETITIVA}

Nas últimas décadas a competição se acentuou drasticamente, aspectos como o advento da tecnologia e suas incessantes mudanças, a relevância do conhecimento e o uso da informação como meio de obter vantagens no mercado são alguns dos responsáveis por essa dimensão. Ademais, a globalização possibilitou a abertura do comércio e a utilização de estratégias globais, viabilizando a busca por materiais e componentes de baixo custo, além de alocar operações por todo o globo.

As formas convencionais de obter vantagens de mercado, como economias de escala e vultosas verbas publicitárias dão lugar às estratégias competitivas onde os novos líderes valorizem a flexibilidade, agilidade, inovação, integração, a confiança e habilidades para lidar com as constantes mudanças (PORTER; 1989, 2009; ZACCARELLI et al., 2008; HITT; IRELAND; HOSKISSON, 2011; BERTOSSO; EBERT; LAIMER, 2017; AGUIAR et al. 2017).

Quanto à perspectiva de competição nos clusters, a inovação e o diferencial estratégico são o principal destaque. Qualquer empresa alheia a um cluster compete não diretamente com alguma empresa integrante do cluster, mas de certa maneira, confronta todo o cluster em si (GILBERT, 2003; ZACCARELLI et al., 2008). 


\subsection{A TEORIA COOPERATIVA}

Na teoria da competição, a ênfase se dá na concorrência, que é descrita como a rivalidade direta entre empresas de mesmo segmento (SILVA, 2016; PANDA, 2017). Durante muito tempo acreditou-se que a extrema rivalidade fosse a interação mais benéfica entre organizações, sendo a cooperação sempre considerada um empecilho à interação competitiva efetiva. Esse ponto de vista mudou e argumentase que é possível atingir vantagens por meio da cooperação entre concorrentes, pois por meio da cooperação, empresas se complementam e aprimoram em diversas áreas como, introdução de novos produtos, produção, entrada em novos mercados, além de vantagens envolvendo redução de custos, de riscos e a formação de alianças estratégicas (BENGTSSON; KOCK, 2000; KWASNICKA; ZACCARELLI, 2006; GERAUDEL; SALVETAT, 2014; PANDA, 2017; SILVA, 2016).

Segundo Nalebuff e Brandenburger (1996), a ação cooperativa pode ser observada, ainda que haja concorrência entre as empresas. A atuação conjunta gera maior inovação, sinergia e desempenho do que isoladamente; quando isso não ocorre, as empresas são expostas a um alto risco da estagnação. As oportunidades de cooperação fomentam projetos ou novos negócios. Para Gray e Wood (1991), as organizações podem conviver num mesmo contexto, cooperando racionalmente a fim de alcançarem objetivos comuns. Essa é uma estratégia que exige confiança entre os participantes, para que realizem a estratégia de forma combinada.

\subsection{A TEORIA COOPETITIVA}

Coopetição traz um novo conceito de relacionamento entre organizações. Nesse novo paradigma os típicos concorrentes podem estar envolvidos em relações tanto competitivas quanto cooperativas simultaneamente e esse mesmo vínculo ocasionar benefícios a ambos (BENGTSSON; KOCK, 2000). A ideia crucial que representa a coopetição é competir sem destruir seus rivais e cooperar sem esquecer seus próprios interesses (NALEBUFF; BRANDENBURGER, 1996).

Para Luo, Slotegraaf e Pan (2006), a coopetição colabora para a aquisição de um amplo conhecimento de mercado, que gera um nível superior de cooperação e amplitude na concorrência, que, por fim, leva a um melhor desempenho financeiro e de mercado. Além do mais, a coopetição estimula aperfeiçoamentos nos produtos, serviços, nas relações com os consumidores, ganhos de qualidade, bem como de produtividade, que não seriam possíveis de alcançar se desenvolvidos separadamente (MONTICELLI, 2015). Entretanto, na coopetição, contrário ao que sucede com a cooperação, o que é melhor para uma organização pode não ser melhor para outra ou para seus objetivos de acréscimo de desempenho. 
Quanto à coopetição em clusters, um bom exemplo é apresentado no estudo de Dana e Granata (2013), que aplicaram sua pesquisa em um cluster de vinhos na Nova Zelândia e constataram não só a presença, como as benesses da coopetição no mesmo. Os autores inferiram que clusters de vinho surgem do anseio coletivo dos produtores de pequeno porte em exportar seus produtos e deste modo diversificar o mercado, o que não seria possível caso atuassem isoladamente.

Portanto, apesar da competição acirrada no ambiente dos negócios incitar estratégias individualistas, estudos empíricos tem demonstrado ser possivel que pequenas e médias constituam alianças estratégicas e cooperem entre si visando objetivos comuns de mercado (LIMA; GEHLEN, 2006). Morais e Zdanowicz (2013, p. 15), ao se referirem à Zacarelli et al., (2008), afirmam haver um diferencial competitivo que se estabelece por meio de transferências e do desenvolvimento compartilhado de competências, ainda que em meio a um cenário de concorrência, característica da coopetição.

\section{PROCEDIMENTOS METODOLÓGICOS}

Com o intuito de atender ao objetivo proposto por esta pesquisa, este capítulo evidencia os métodos e técnicas utilizados para o desenvolvimento do estudo e traz, em seu contexto, a sua caracterização, a metodologia para a coleta de dados e o processo de análise dos dados, assumidos a partir de uma pesquisa descritiva, de natureza quantitativa.

\subsection{OBJETO DE ESTUDO E ELEMENTO DE ANÁLISE}

O objeto de estudo desta pesquisa é o aglomerado varejista alimentício localizado no centro da cidade de Aracaju, capital do Estado de Sergipe-SE, o Mercado Municipal Maria Virgínia Leite Franco. Foi realizado o levantamento da quantidade de boxes junto ao site da Prefeitura Municipal de Aracaju (PMA), identificando 852 boxes.

\subsection{AMOSTRA, UNIVERSO E SUJEITOS DA PESQUISA}

Com base na visita técnica no departamento que administra o mercado, foi confirmado o quantitativo de 852 boxes. Desse total, identificou-se 216 boxes que integram o segmento alimentício de frutas, legumes, verduras e hortaliças, sendo estes considerados como foco dessa pesquisa. Cabe destacar que os segmentos de carnes, pescados e rações, integrantes do segmento alimentício, não foram considerados na pesquisa, portanto, não integram os 216 boxes selecionados para estudo. Quanto aos sujeitos da pesquisa, foram elegidos os proprietários ou pessoas responsáveis pelos estabelecimentos estudados. 
Definido o universo (população), parte-se então para o estabelecimento do tamanho da amostragem. Para isso foi utilizada a fórmula para o cálculo de amostras para populações finitas, aquelas que não ultrapassam 100.000 elementos (BUSSAB; MORETTIN, 1986 apud SILVA, 2016, p.103).

Onde: $\mathrm{n}=$ Tamanho da amostra; $\sigma^{2}=$ Nivel de confiança de $95 \%$ equivalente a 1,96; $\mathrm{p}$ = Percentagem com que o fenômeno se verifica $(0,5) ; \mathrm{q}=$ Percentagem complementar; $\mathrm{N}=$ Tamanho da população; $\mathrm{e}^{2}=$ Erro máximo permitido (5\%).

Realizado o cálculo amostral para populações finitas, com índice de confiança de 95\% e margem de erro de 5\%, aferiu-se o valor final de 139. Portanto, tem-se como universo 216 boxes e como amostra 139 boxes do segmento alimentício constituído de frutas, verduras, legumes e hortaliças selecionados para pesquisa. Importante salientar uma limitação apresentada na pesquisa devido ao número de 120 feirantes que se propuseram a responder o instrumento.

\subsection{INSTRUMENTO DE PESQUISA}

O instrumento de pesquisa utilizado é uma ferramenta validada por Silva (2016), sendo composta por três construtos: competição, cooperação e coopetição. $O$ instrumento foi submetido a adaptações decorrentes das mudanças quanto ao objeto e cenário da pesquisa. Salienta-se que as variáveis V1 a V6 caracterizam o perfil dos entrevistados. No Quadro 1 é possível visualizar detalhadamente todas as variáveis referentes aos três construtos determinados como foco desse estudo. 
Quadro 1 - Indicadores do Instrumento de Pesquisa

\begin{tabular}{|c|c|}
\hline Dimensão & Variáveis \\
\hline Cooperação & $\begin{array}{l}\text { V7 - Os lojistas trocam experiências e aprendizagens junto aos demais lojistas do mercado. } \\
\text { v8 - As atividades conjuntas entre os lojistas são realizadas em um clima de confiança. } \\
\text { v9- Os lojistas compartilham conhecimentos, tais como leis que regem o setor e conhecimentos } \\
\text { técnicos. } \\
\text { v10 - Na eventualidade de não poder atender o cliente, os lojistas costumam indicar } \\
\text { estabelecimentos concorrentes. } \\
\text { V11 - Os lojistas trocam informações uns com os outros sobre os fornecedores. } \\
\text { V12 - Os lojistas trocam informações uns com os outros sobre os clientes. } \\
\text { v13 - Os lojistas trocam informações uns com os outros sobre as tendências de consumo. } \\
\text { v14 - Os lojistas trocam informações uns com os outros sobre como administrar seus negócios. } \\
\text { v15 - Os lojistas compartilham uns com os outros sobre o surgimento de novos produtos. } \\
\text { v16 - Os lojistas desenvolvem atividades de ajuda com os demais lojistas do mercado. } \\
\text { v17 - Existe comunicação entre os lojistas do mercado } \\
\text { v18 - Os lojistas desenvolvem ações de colaboração entre eles para melhorias do mercado } \\
\text { municipal. }\end{array}$ \\
\hline Competição & $\begin{array}{l}\text { V19 - A competição entre os lojistas é acirrada. } \\
\text { V20 - A concorrência em aparência física do estabelecimento aumenta a competição entre as } \\
\text { lojas do mercado. } \\
\text { V21 -A concorrência acerca do melhor atendimento aumenta a competição entre as lojas do } \\
\text { mercado. } \\
\text { V22 - A concorrência em preços e promoçães dos produtos aumenta a competição entre as } \\
\text { lojas do mercado. } \\
\text { V23 - A concorrência sobre as características dos produtos disponibilizados para venda } \\
\text { aumenta a competição entre as lojas do mercado. } \\
\text { V24 - Estar localizado em uma concentração de lojas do mesmo segmento influencia a } \\
\text { concorrência do mercado. } \\
\text { V25 - Neste mercado municipal há uma concorrência mais forte do que a concorrência de lojas } \\
\text { "isoladas" (não integrantes desse mercado). } \\
\text { V26 - A concorrência contribui para a sobrevivência das lojas do mercado. } \\
\text { V27 - Existem conflitos de interesses financeiros/econômicos entre os lojistas do mercado. } \\
\text { V28 - Existe rivalidade entre os lojistas do mercado. } \\
\text { V29 - Os estabelecimentos de grande porte deste mercado influenciam no fechamento dos } \\
\text { estabelecimentos menores. } \\
\text { V30 - Sempre que possível os lojistas do mercado tomam clientes de seus concorrentes. } \\
\text { V31 - Sempre que possível os lojistas do mercado copiam os procedimentos de outros lojistas } \\
\text { concorrentes. } \\
\text { V32 - A concorrência pela liderança de mercado (ser o melhor) é comum no mercado. } \\
\text { V33 - Os funcionários são utilizados para avaliar o comportamento de vendas dos concorrentes. } \\
\text { V34 - Existem informações falsas que circulam sobre os concorrentes do mercado. }\end{array}$ \\
\hline
\end{tabular}




\begin{tabular}{|c|c|}
\hline Coopetição & 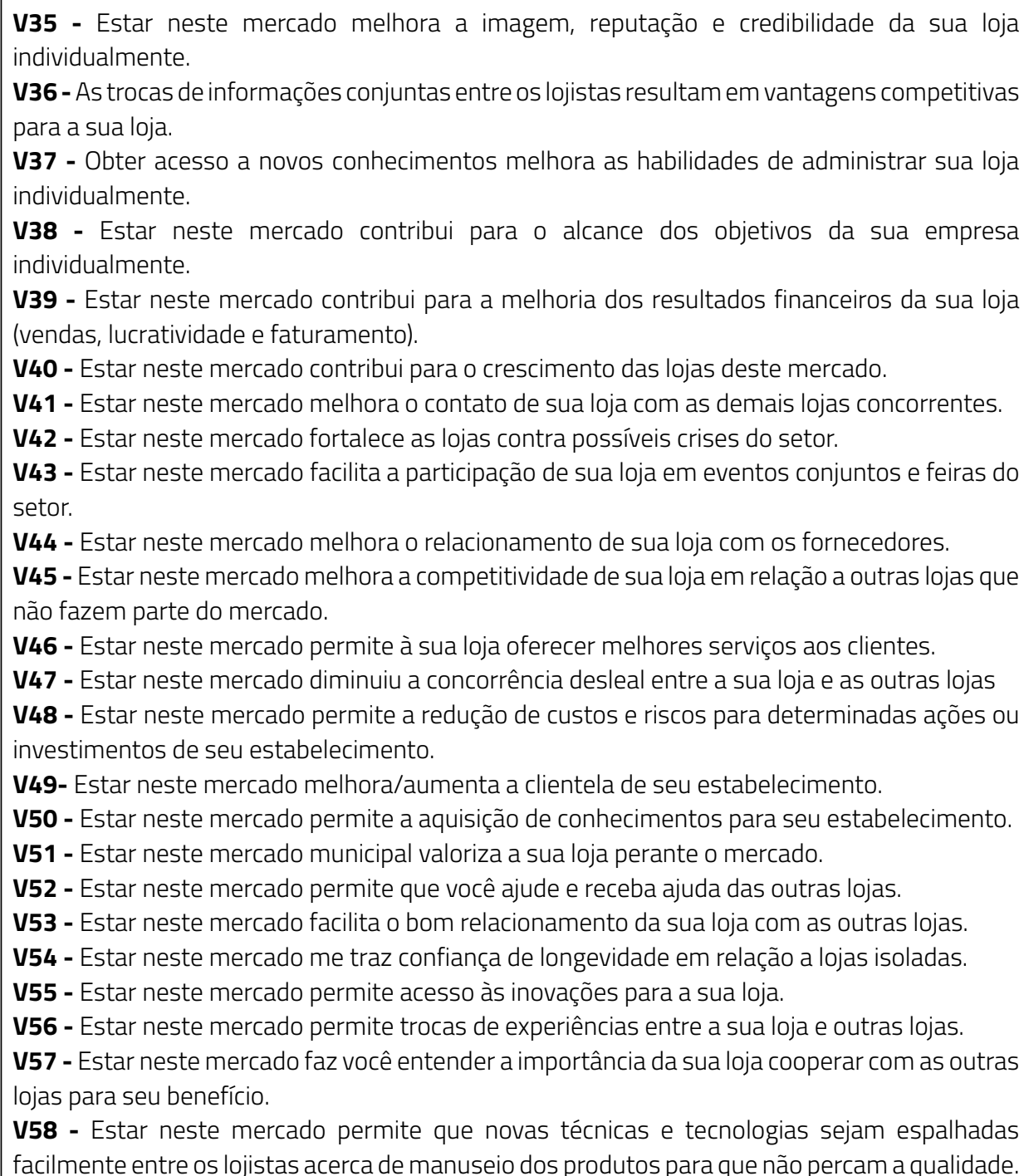 \\
\hline
\end{tabular}

\section{Fonte: Silva (2016, p. 105-108).}

Dessa forma, por meio da ferramenta validada por Silva (2016), realizou-se a formatação do instrumento de pesquisa da maneira mais apropriada para o desenvolvimento do estudo, buscando-se, em seguida, a realização da coleta de dados junto aos pequenos feirantes do aglomerado alimentício, para identificar os fatores formadores da cooperação, competição e coopetição. 


\subsection{PROCEDIMENTOS PARA TRATAMENTO E ANÁLISE DE DADOS}

Os dados necessários para a consecução do objetivo da pesquisa foram obtidos por meio do procedimento de pesquisa do tipo survey, intermediado com um questionário aplicado pessoalmente pelos pesquisadores com 120 feirantes, empregando uma escala bipolar de zero a dez para respostas de cada uma das 58 perguntas. A representação escalar considera zero igual à discordância total e 10 igual à concordância total. Após o levantamento dos dados, provenientes das aplicações dos questionários, foi realizada a tabulação por meio do software Microsoft Excel, e posteriormente os dados foram tratados no software IBM SPSS (Statistic Package for Social Science).

Para atender ao objetivo proposto pautado em identificar os fatores formadores da cooperação, competição e coopetição entre os feirantes, utilizou-se o método quantitativo de Análise Fatorial Exploratória (AFE), uma vez que não se conhecia antecipadamente o vínculo de dependência entre as variáveis e nem se os fatores possuíam uma estrutura de relação ou se essa estrutura poderia ser elucidada (CORRAR; PAULO; DIAS FILHO, 2009, p. 74).

\section{ANÁLISE DOS RESULTADOS E CONSIDERAÇõES TEÓRICAS}

Este capítulo trata das análises dos resultados, delimitado em três momentos: caracterização das empresas pesquisadas, tratamento dos dados por meio da Análise Fatorial Exploratória e discussão teórica dos resultados.

\subsection{CARACTERIZAÇÃO DAS EMPRESAS PESQUISADAS}

Do total de 120 feirantes pesquisados, 44\% são do sexo masculino e 55\% feminino. Quanto a escolaridade, houve uma concentração ensino fundamental incompleto, com 49\%, seguido do ensino médio completo, com 30\%. Os demais ficaram entre superior completo e incompleto. Em relação aos produtos que são comercializados pelos feirantes, a predominância ficou com as lojas que vendem todos os tipos de alimentos e com as que vendem somente frutas, com respectivamente 35\% e 33,33\%. 0 tempo mínimo de existência identificado entre so feirantes ficou em 4 meses e o tempo máximo em 60 anos.

\subsection{ANÁLISE FATORIAL EXPLORATÓRIA DOS CONSTRUTOS}

Essa pesquisa utilizou a Análise Fatorial Exploratória (AFE), como método de análise multivariada. Esse método se torna eficaz em situações onde o pesquisador desconhece as relações entre as variáveis e se há coerência entre as mesmas (CORRAR; PAULO; DIAS FILHO, 2009). Para Silva (2016), a AFE também serve para redução de dados ou simplificação da estrutura. 


\subsection{ANÁLISE DAS PREMISSAS DA ANÁLISE FATORIAL EXPLORATÓRIA (AFE)}

Nessa seção são expostas as premissas da AFE, segundo Prearo et al. (2011 apud SILVA, 2016), essas premissas vão desde o tamanho da amostra, normalidade multivariada e multicolinearidade através dos testes de Esfericidade de Bartlett's, Kaiser Meyer Olkin (KMO), Measure of Sampling Adequacy (MSA).

É importante elencar que, no que se refere ao tamanho da amostra indicada no Quadro 2, Hair et al. (2009), assevera que os resultados propostos, tendo validade discriminante, é possivel dar continuidade nas análises, que é o caso dessa pesquisa. Quanto ao KMO e o MSA, esses são melhor detalhados ao longo da explanação de cada construto. No que se refere à normalidade multivariada, por se tratar de uma amostragem com um número relativamente alto, é possível eliminar essa premissa da pesquisa (EISENBEIS, 1977, 1994 apud SILVA, 2016).

\subsubsection{Análise Fatorial Exploratória do Construto Cooperação/Colaboração}

O construto cooperação/colaboração é formado por 12 variáveis (V7 a V18). Foram realizadas duas tentativas para obtenção de uma AFE que atingisse todas as premissas, sendo retirada a variável V10 no segundo teste, pois sua comunalidade estava abaixo de 0,50, não atendendo esta premissa conforme indicações de Corrar, Paulo e Dias Filho (2009).

Na segunda tentativa, o valor do KMO apresentou um índice de 0,873, sendo considerado bom dentro dos padrões estabelecidos, tendo em vista que o teste KMO que possui uma variação entre 0 e 1 e é um teste que calcula o nivel de correspondência parcial entre as variáveis. Quando o valor fica mais próximo de zero pode indicar inadequação do uso da análise fatorial, pois haverá uma relação frágil entre as variáveis (PESTANA; GAGEIRO, 2000 apud BELFIORE; FÁVERO; ANGELO, 2005).

Quanto ao teste de Esfericidade de Bartlett's, este "indica se existe relação suficiente entre os indicadores para aplicação da AFE" (CORRAR; PAULO; DIAS FILHO, 2009). Para que se possa aplicar a AFE, "recomenda-se que o valor de Sig (teste de significância) não ultrapasse 0,05" (CORRAR; PAULO; DIAS FILHO, 2009). Tendo como retorno na segunda análise do construto cooperação/colaboração um índice de significância de 0,00 no teste de Esfericidade de Bartlett's, o que significa ser possível dar sequência à AFE, visto que há relação entre as variáveis.

O MSA indica o nível de elucidação dos dados com base nos fatores descobertos na AFE. Onde indices menores que 0,50 indicam que esses fatores não representam de forma satisfatória as variantes dos dados originais (CORRAR; PAULO; DIAS FILHO, 2009). Na segunda tentativa os valores da matriz antiimagem apresentam grau de MSA adequado, com menor valor de 0,783 e maior de 0,933, ou seja, muito 
além dos 0,50 estabelecidos. Conseguindo assim descrever de forma satisfatória as variações dos dados iniciais.

Outra análise importante é a comunalidade, a qual significa a "quantia total de variância que uma variável original compartilha com todas as outras variáveis incluídas na análise" (HAIR et al., 2009, p. 101). Na AFE as variáveis são agrupadas de maneira que fiquem correlacionadas, assim, variáveis em um grupo (fator) possuem níveis altos de correlações umas com as outras. Visto isso, a comunalidade surge para compreender que quantia da variância de uma variável é repartida com outras variáveis (HAIR et al., 2009). Para Hair et al. (2009), a comunalidade deve ter valor maior que 0,50 para poder prosseguir na análise. Na segunda tentativa, com a retirada da V10 o menor valor dentro da comunalidade foi de 0,509, ou seja, nenhuma das variáveis apresentou valor menor que 0,50, cumprindo assim o objetivo de relacionar variáveis e fatores.

Além disso, deve-se também analisar o fator de explicação alcançado pelos fatores da AFE (CORRAR; PAULO; DIAS FILHO, 2009). Segundo Hair et al. (2009), nas ciências sociais devido os dados resultantes das pesquisas serem imprecisos, é aceitável que a variância total explicada alcance um valor mínimo de $60 \%$. A variância total explicada com a retirada da V10 apresentou índice de 65,05\%.

A funcionalidade da AFE se dá por meio da possibilidade de se gerar fatores que possam ser interpretados. Entretanto, existem casos em que mais de um fator explica o comportamento de determinada variável da problemática investigada. Nessas situações utiliza-se a rotação, que procuram resoluções que expliquem o mesmo nível de variância total, porém gerando resultados superiores em referência à sua interpretação. A rotação não modifica o total, da variância atingida anteriormente, apenas reorganiza os autovalores.

Nessa pesquisa foi utilizado o Varimax, um tipo ortogonal de rotação que tem como destaque possibilitar de maneira mais fácil que uma variável seja apontada em um único fator. (CORRAR; PAULO; DIAS FILHO, 2009). Por fim, o Varimax apresentou na segunda tentativa, fatores bem discriminados. Devido todas as premissas terem sido concretizadas, esta é considerada uma boa AFE. Após a segunda rotação o construto cooperação/colaboração ficou composto por dois fatores. 0 fator 1 é formado pelas variáveis V16, V8, V18, V9, V7, V11. Já o fator 2 é composto pelas variáveis V13, V14, V12, V15. Com isso se encerra a necessidade de outras tentativas, visto que todas as premissas foram atingidas. Hair et al. (2009), consideram que nomear os fatores constitui tarefa subjetiva do responsável pela pesquisa. Com isso, foi realizada a nomeação dos dois fatores resultantes das análises. Através da Tabela 1 é possível averiguar a separação, nomeação e nivel de carga fatorial dos fatores. 


\begin{tabular}{|c|c|c|}
\hline Fatores & Variáveis & Carga Fatorial \\
\hline \multirow{7}{*}{$\begin{array}{c}\text { Fator 1: Ações } \\
\text { Conjuntas } \\
\text { (AC) }\end{array}$} & $\begin{array}{l}\text { V16 - Os lojistas desenvolvem atividades de ajuda com os demais } \\
\text { lojistas do mercado. }\end{array}$ & $\underline{0,769}$ \\
\hline & $\begin{array}{l}\text { vs - As atividades conjuntas entre os lojistas são realizadas em um } \\
\text { clima de confiança. }\end{array}$ & 0,754 \\
\hline & $\begin{array}{l}\text { v1s - Os lojistas desenv olvem ações de colaboração entre eles para } \\
\text { melhorias do mercado municipal. }\end{array}$ & 0,751 \\
\hline & \begin{tabular}{|l|l} 
V17 - Existe comunicação entre os lojistas do mercado \\
\end{tabular} & 0,732 \\
\hline & $\begin{array}{l}\text { V9 - Os lojistas compartilham conhecimentos, tais como leis que } \\
\text { regem o setor e conhecimentos técnicos. }\end{array}$ & 0,703 \\
\hline & $\begin{array}{l}\text { V7 - Os lojistas trocam experiências e aprendizagens junto aos } \\
\text { demais lojistas do mercado. }\end{array}$ & 0,665 \\
\hline & $\begin{array}{l}\text { V11 - Os lojistas trocam informações uns com os outros sobre os } \\
\text { fornecedores. }\end{array}$ & 0,584 \\
\hline \multirow{4}{*}{$\begin{array}{l}\text { Fator 2: Troca de } \\
\text { Informações } \\
\text { (TI) }\end{array}$} & $\begin{array}{l}\text { V13 - Os lojistas trocam informações uns com os outros sobre as } \\
\text { tendências de consumo. }\end{array}$ & $\underline{0,894}$ \\
\hline & $\begin{array}{l}\text { V14 - Os lojistas trocam informações uns com os outros sobre como } \\
\text { administrar seus negócios. }\end{array}$ & 0,851 \\
\hline & $\begin{array}{l}\text { v12 - Os lojistas trocam informações uns com os outros sobre os } \\
\text { clientes. }\end{array}$ & 0,847 \\
\hline & $\begin{array}{l}\text { V15 - Os lojistas compartilham uns com os outros sobre o } \\
\text { surgimento de novos produtos. }\end{array}$ & 0,743 \\
\hline
\end{tabular}

Fonte: Dados da Pesquisa (2019).

Assim, o construto Cooperação/Colaboração foi particionado em dois fatores, ações conjuntas (AC) e troca de informações (TI).

\subsubsection{Considerações Teóricas Relativas ao Constructo Cooperação/Colaboração}

Relacionando a teoria à pesquisa realizada, tem-se, inicialmente, o fator 1 nomeado de ações conjuntas (AC), que apresenta em sua estrutura características difundidas por autores como Bengtsson e Kock (2000) e Balestrin e Verschoore (2008), que afirmam que relações cooperativas são baseadas na confiança e em interesses recíprocos e que a cooperação restringe o oportunismo e fortalece as relações interorganizacionais. Os autores também defendem o uso de estratégias colaborativas que estimulem, por exemplo, fornecedores e fabricantes a atuar em conjunto, pois qualquer melhoria desenvolvida geraria retorno para ambos.

Assim, face ao resultado exposto do fator 1 ações conjuntas, foi possivel corroborar com os estudos de Silva (2016 p.136), uma vez que "por meio desses relacionamentos interorganizacionais e ações conjuntas, numa concentração geográfica, as empresas podem alcançar vantagem competitiva". A autora destaca, ainda, que as estratégias colaborativas possibilitam às empresas adquirir habilidades antes não observadas, já que essas passam a ser utilizadas na geração de inovação e crescimento de receita; gestão de talentos e desenvolvimento de lideranças; melhoria da conectividade com o cliente; eficácia da força de vendas; execução e alinhamento da estratégia; retorno financeiro mediante colaboração eficaz, bem 
como na transferência das melhores práticas adotadas pelas empresas pertencentes à aglomeração ou cluster.

O fator 2, troca de informações (TI), segue a teoria de Zaccarelli et al. (2008), que indicam como efeito da cooperação o "aumento da capacidade competitiva do cluster devido à impossibilidade de contenção de troca de informações entre negócios" (ZACCARELLI et al., 2008, p. 215). Já Balestrin e Verschoore (2008), afirmam que tanto a troca de informações como a troca de conhecimentos são favorecidas pela cooperação, bem como pela confiança entre os atores, pois quando se trata de pequenos negócios a confiança ocorre por meio da "integridade, que é baseada na aderência do comportamento de um parceiro a um determinado conjunto de normas aceitas como justas e corretas pelos outros membros do grupo" (BERTOSSO; EBERT; LAIMER, 2017 p.310), ou seja, não é construída com base em contratos, mas em mecanismos não contratuais (SILVA, 2016; PANDA, 2017).

\subsubsection{Análise Fatorial Exploratória do Construto Competição}

O construto competição é formado por um conjunto de 16 variáveis (da variável V19 a V34). Contudo, foi necessário realizar seis tentativas, sendo retiradas as variáveis V29, V26, V19, V32 e V24, pois essas não atenderam a comunalidade a partir de 0,50 (CORRAR; PAULO; DIAS FILHO, 2009) para uma AFE satisfatória, bem como atender as premissas do método.

Na sexta tentativa, foi removida a V24, onde o KMO atingiu índice de 0,794. 0 teste de Esfericidade de Bartlett's obteve sig 0,00 e todos os valores do MSA representam de forma adequada as variações dos dados originários, haja vista que, todos os índices apresentam valores acima de 0,50. Por fim, todos os índices da comunalidade atingiram o mínimo de 0,50, tendo como menor deles 0,542 e como maior 0,862, com isso a correlação entre os fatores se concluiu. 0 fator de explicação atingiu o maior índice dentre todas as tentativas efetuadas, com $66,38 \%$, permitindo assim uma melhor explicação dos fatores calculados pela AFE.

Na sexta rodada, a comunalidade de todas as variáveis atingiu o valor necessário, com isso a reorganização das variáveis para que cada uma encontre seu fator correlacionado através do método varimax foi concluída. Assim, devido todas as premissas terem sido atingidas, chegou-se a uma AFE com validade discriminante.

Os fatores ficaram subdivididos em três: fator 1, formado pelas variáveis V23, V21, V22, V20; o fator 2, formado por V34, V30, V33, V31, e por fim o fator 3, formado por V25, V27, V28. Na Tabela 2 é possível verificar a nomenclatura dos fatores e a carga fatorial de cada uma das variáveis em seu determinado fator. 
Tabela 2 - Terminologia dos fatores do Construto Competição

\begin{tabular}{|c|c|c|}
\hline Fatores & Variáveis & Carga Fatorial \\
\hline \multirow{4}{*}{$\begin{array}{l}\text { Fator 1: Concorrência } \\
\text { (CONC) }\end{array}$} & $\begin{array}{l}\text { V23 - A concorrência sobre as características dos produtos } \\
\text { disponibilizados para venda aumenta a competição entre as lojas do } \\
\text { mercado. }\end{array}$ & $\underline{0,913}$ \\
\hline & $\begin{array}{l}\text { V21 -A concorrência acerca do melhor atendimento aumenta a } \\
\text { competição entre as lojas do mercado. }\end{array}$ & 0,871 \\
\hline & $\begin{array}{l}\text { V22 - A concorrência em preços e promoções dos produtos aumenta } \\
\text { a competição entre as lojas do mercado. }\end{array}$ & 0,863 \\
\hline & $\begin{array}{l}\text { V20 - A concorrência em aparência física do estabelecimento } \\
\text { aumenta a competição entre as lojas do mercado. }\end{array}$ & 0,816 \\
\hline \multirow{4}{*}{$\begin{array}{l}\text { Fator 2: Comportamento } \\
\text { Oportunista } \\
\text { (CO) }\end{array}$} & $\begin{array}{l}\text { V34 - Existem informações falsas que circulam sobre os } \\
\text { concorrentes do mercado. }\end{array}$ & $\underline{0,796}$ \\
\hline & $\begin{array}{l}\text { V30 - Sempre que possivel os lojistas do mercado tomam clientes } \\
\text { de seus concorrentes. }\end{array}$ & 0,738 \\
\hline & $\begin{array}{l}\text { V33 - Os funcionários são utilizados para avaliar o comportamento } \\
\text { de vendas dos concorrentes. }\end{array}$ & 0,733 \\
\hline & $\begin{array}{l}\text { V31 - Sempre que possivel os lojistas do mercado copiam os } \\
\text { procedimentos de outros lojistas concorrentes. }\end{array}$ & 0,709 \\
\hline \multirow{3}{*}{$\begin{array}{l}\text { Fator 3: Competitividade do } \\
\text { Aglomerado } \\
\text { (CA) }\end{array}$} & $\begin{array}{l}\text { V25 - Neste mercado municipal há uma concorrência mais forte do que a } \\
\text { concorrência de lojas "isoladas" (não integrantes desse mercado). }\end{array}$ & $\underline{0,728}$ \\
\hline & $\begin{array}{l}\text { V27 - Existem conflitos de interesses financeiros/econômicos entre } \\
\text { os lojistas do mercado. }\end{array}$ & 0,727 \\
\hline & V28 - Existe rivalidade entre os lojistas do mercado. & 0,704 \\
\hline
\end{tabular}

\section{Fonte: Dados da pesquisa (2019)}

Com isso, o construto competição ficou formado por três fatores: concorrência (CONC), comportamento oportunista (CO) e competitividade do aglomerado (CA).

\subsubsection{Considerações Teóricas Relativas ao Construto Competição}

Após a conclusão da análise do construto competição, a associação entre teoria e pesquisa fazse necessária. No fator 1, concorrência (CONC), com maior carga fatorial $(0,913)$ nomeado por meio da variável 23 'a concorrência sobre as características dos produtos disponibilizados para venda aumenta a competição entre as lojas do mercado', face ao exposto, a concorrência disposta no aglomerado estudado relaciona-se, por exemplo, aos estudos de Porter (1989, 2009), ao asseverar que a concorrência sobre as características dos produtos disponibilizados para venda aumenta a competição entre empresas pertencentes ao cluster, consequentemente começam a surgir empresas com diferencial estratégico por meio da inovação, emergindo um ciclo vicioso como características de relevância nas relações competitivas dentro dos aglomerados (clusters) (ZACCARELLI et al., 2008).

No fator 2, comportamento oportunista (CO), a maior carga fatorial é a da V34 (0,796), 'existem informações falsas que circulam sobre os concorrentes do mercado.' Por meio da teoria de autores como Porter (2009); Balestrin e Verschoore, (2008); Zaccarelli et al. (2008); Bertosso, Ebert e Laimer (2017); 
e Silva (2016) foi possível corroborar com os resultados evidenciados, pois segundo esses autores, os relacionamentos interorganizacionais entre atores de um aglomerado não é simples, sendo baseado em confiança e havendo sempre o risco do oportunismo e das trapaças.

Por fim, no fator 3, competitividade do aglomerado (CA), a maior carga fatorial alcançada foi na V25 $(0,728)$, 'neste mercado municipal há uma concorrência mais forte do que a concorrência de lojas isoladas (não integrantes desse mercado).' Autores como Telles (2008); Zaccarelli et al. (2008); Aguiar et al. (2017), afirmam que os aglomerados ampliam as capacidades competitivas de seus integrantes e os tornam mais capacitados a ganhar de seus adversários na disputa pela preferência dos clientes em relação a empresas isoladas, no qual também é confirmado na pesquisa de Silva (2016).

Outras fundamentações da pesquisa se dão com base em Teller (2008), Siqueira, Gerth, Boaventura (2011) e Silva (2016), no qual afirmam que dentro dos aglomerados há competição por participação de mercado, funcionários e recursos, ou seja, por ofertarem uma diversidade de mercadorias e atraírem o mesmo tipo de clientela.

\subsubsection{Análise Fatorial Exploratória do Construto Coopetição}

O construto coopetição teve em sua formação inicial um total de 24 variáveis (da variável V35 até a V58). Nesse construto, foi necessário realizar 13 tentativas (rodadas) até que fosse alcançada uma AFE satisfatória que atendesse todas as premissas. Sendo eliminadas as variáveis V35, V48, V44, V42, V41, V56, V55, V45, V47, V54, V43 e V40.

Na décima terceira e última análise, o valor de KMO ficou em 0,778 e o teste de Esfericidade de Bartlett's com sig 0,00. No resultado da matriz MSA, nenhum índice ficou abaixo dos 0,50 mínimos para representar adequadamente as variações das informações originais. Quanto à comunalidade todas as variáveis atingiram índices acima dos 0,50, conforme recomendado. No que se refere à variância total explicada, esta atingiu um total de $73,11 \%$, ou seja, valor acima do mínimo de $60 \%$ recomendados, mostrando-se assim adequado para realização de uma boa AFE. A rotação ortogonal varimax finalmente apresentou resultados satisfatórios, com agrupamento claro dos fatores.

Com isso, finalizam-se todos os testes, sendo agora fundamental a determinação dos fatores de acordo com o que foi obtido da rotação ortogonal varimax. São 4 fatores, sendo eles divididos em: fator 1 , constituído por V50, V51, V46 e V49; fator 2, formado por V38, V37 e V39; fator 3, composto por V57 e V58, e por fim, fator 4 formado por V52, V36 e V53. Na Tabela 3 são apresentadas as características dos fatores. 
Tabela 3 - Terminologia dos fatores do Construto Coopetição

\begin{tabular}{|c|c|c|}
\hline Fatores & Variáveis & Carga Fatorial \\
\hline \multirow{4}{*}{$\begin{array}{l}\text { Fator 1: Localização } \\
\text { (LOC) }\end{array}$} & $\begin{array}{l}\text { v50 - Estar neste mercado permite a aquisição de conhecimentos } \\
\text { para seu estabelecimento. }\end{array}$ & $\underline{0,876}$ \\
\hline & $\begin{array}{l}\text { v51 - Estar neste mercado municipal valoriza a sua loja perante o } \\
\text { mercado. }\end{array}$ & 0,819 \\
\hline & $\begin{array}{l}\text { V46 - Estar neste mercado permite à sua loja oferecer melhores } \\
\text { serviços aos clientes. }\end{array}$ & 0,681 \\
\hline & $\begin{array}{l}\begin{array}{l}\text { V49- Estar neste mercado melhora/aumenta a clientela de seu } \\
\text { estabelecimento. }\end{array} \\
\end{array}$ & 0,673 \\
\hline \multirow{3}{*}{$\begin{array}{l}\text { Fator 2: Desenvolvimento da } \\
\text { Empresa } \\
\text { (DE) }\end{array}$} & $\begin{array}{l}\text { V38 - Estar neste mercado contribui para o alcance dos objetiv os da } \\
\text { sua empresa individualmente. }\end{array}$ & $\underline{0,864}$ \\
\hline & $\begin{array}{l}\text { V37 - Obter acesso a nov os conhecimentos melhora as habilidades } \\
\text { de administrar sua loja indiv idualmente. }\end{array}$ & 0,826 \\
\hline & $\begin{array}{l}\text { V39 - Estar neste mercado contribui para a melhoria dos resultados } \\
\text { financeiros da sua loja (vendas, lucratividade e faturamento). }\end{array}$ & 0,665 \\
\hline \multirow{2}{*}{$\begin{array}{l}\text { Fator 3: Colaboração } \\
\text { (COL) }\end{array}$} & $\begin{array}{l}\text { V57 - Estar neste mercado faz você entender a importância da sua } \\
\text { loja cooperar com as outras lojas para seu benefício. }\end{array}$ & $\underline{0,863}$ \\
\hline & $\begin{array}{l}\text { V58 - Estar neste mercado permite que novas técnicas e tecnologias } \\
\text { sejam espalhadas facilmente entre os lojistas acerca de manuseio } \\
\text { dos produtos para que não percam a qualidade. }\end{array}$ & 0,812 \\
\hline \multirow{3}{*}{$\begin{array}{l}\text { Fator 4: Relacionamentos } \\
\text { Interorganizacionais (RIOS) }\end{array}$} & $\begin{array}{l}\text { V52 - Estar neste mercado permite que você ajude e receba ajuda } \\
\text { das outras lojas. }\end{array}$ & $\underline{0,851}$ \\
\hline & $\begin{array}{l}\text { V36 - As trocas de informações conjuntas entre os lojistas resultam } \\
\text { em vantagens competitivas para a sua loja. }\end{array}$ & 0,691 \\
\hline & $\begin{array}{l}\text { V53 - Estar neste mercado facilita o bom relacionamento da sua loja } \\
\text { com as outras lojas. }\end{array}$ & 0,613 \\
\hline
\end{tabular}

Fonte: Dados da pesquisa (2019)

\subsubsection{Considerações Teóricas Relativas ao Construto Coopetição}

Com base nos resultados, cabe então a aferição dos mesmos em relação à teoria. No fator 1 , localização (LOC), a variável com maior carga fatorial foi a V50, com índice 0,876, 'estar neste mercado permite a aquisição de conhecimentos para seu estabelecimento'. A localização é uma característica identificada por autores como Porter (1998, 1989), Marshall (1996), Zaccarelli et al. (2008), como uma das particularidades de um cluster.

No fator 2, desenvolvimento da empresa (DE), a maior carga fatorial foi na V38 $(0,864)$, 'estar neste mercado contribui para o alcance dos objetivos da sua empresa individualmente.' Nesse fator, foram designados os atributos relacionados às vantagens individuais que são obtidas por meio da associação entre empresas. Para Porter (1989, 2009), a competição em aglomerados tem como foco inovação e diferencial estratégico, que são elementos que terminam por evoluir não apenas o aglomerado, mas a empresa em si, visto que as melhorias que ocorrem mutuamente, não impedem a competição dentro do mesmo. 
Quanto ao fator 3, colaboração (COL), constata-se convergência com as vantagens oriundas da colaboração interfirmas, dentre as quais pode-se citar partilha de maquinário, elaboração de novas tecnologias, ajuda em emergências e aprendizagem coletiva (BALESTRIN; VERSCHOORE, 2008; BALESTRIN; VERSCHOORE; REYES JÚNIOR 2010; FERREIRA; STOROPOLI; SERRA, 2014; KLEIN; ALVES; PEREIRA, 2015; BALESTRIN; SILVA, 2016;VERSCHOORE, 2016; BERTOSSO; EBERT; LAIMER, 2017;PANDA, 2017).

Por último, no fator 4, relacionamentos interorganizacionais (RIOS), a maior carga fatorial se verificou na V52 (0,852), 'estar neste mercado permite que você ajude e receba ajuda das outras lojas'. Como citado anteriormente, segundo Zaccarelli et al. (2008), a cooperação é um dos fundamentos que estruturam um aglomerado, essa cooperação estimula a troca de informações e com isso impulsiona a competição entre os atores pertencentes ao cluster. Para Porter (2009), as empresas pertencentes a um cluster buscam ajudar-se mutuamente, com o intuito de fortalecer o cluster, combatendo assim as ameaças externas e aproveitando as oportunidades.

Essas propriedades apresentadas demonstram a presença tanto da cooperação quanto da competição simultaneamente dentro do aglomerado estudado, que são os elementos formadores da coopetição. Havendo assim relação entre teoria e pesquisa realizada de Silva (2016).

\section{CONSIDERAÇÕES FINAIS}

O objetivo central desta pesquisa foi identificar os fatores formadores da cooperação, competição e coopetição existentes entre pequenos feirantes do aglomerado alimentício do Mercado Municipal Maria Virgínia Leite Franco, considerado um cluster planejado na cidade de Aracaju-SE.

Os resultados do estudo consentiram com a identificação e análise dos elementos presentes nas relações entre os comerciantes do cluster, evidenciando os fatores formadores de cada construto estudado, a saber: i) Cooperação/colaboração: Ações Conjuntas (AC) e Troca de Informações (TI); ii) Competição: Concorrência (CONC), Comportamento Oportunista (CO) e Competitividade do Aglomerado (CA); e iii) Coopetição: Localização (LOC), Desenvolvimento da Empresa (DE), Colaboração (COL) e Relacionamentos Interorganizacionais (RIOS).

Deste modo, constata-se que, pretendendo interesses comuns e recíprocos, os feirantes do cluster estudado, estabelecem entre si relacionamentos de cooperação/colaboração, firmados principalmente na confiança. À medida que esses relacionamentos são aprimorados nas ações conjuntas (AC) e nas trocas de informações (TI) no ambiente de negócios da feira, o conjunto aglomerado combate ao comportamento oportunismo (CO) e a trapaça, ao mesmo tempo que desenvolve uma eficiência coletiva que converge 
para criação de vantagens competitivas das empresas instaladas, muitas vezes não alcançada na atuação individual (BENGTSSON; KOCK, 2000; KWASNICKA; ZACCARELLI, 2006; BALESTRIN; VERSCHOORE, 2008; ZACCARELLI et al., 2008; MONTICELLI, 2015; SILVA, 2016; BERTOSSO; EBERT; LAIMER, 2017).

Outro aspecto consigna-se na percepção de que simultaneamente ao processo de cooperação/ colaboração entre os feirantes do cluster alimentício, transcorre também certo espírito de concorrência (CONC) e competição (individualismo). Esta evidência constatada na disputa pela preferência dos clientes e por predileção entre os fornecedores, por exemplo, ao contrário de ser vista como danosa, contribui para o aprimoramento das capacidades competitivas dos feirantes, possibilitando, em uma perspectiva superior, o desenvolvimento do aglomerado (PORTER, 1989, 2009; GILBERT, 2003; ZACCARELLI et al., 2008; TELLES, 2008; BERTOSSO; EBERT; LAIMER, 2017).

Por fim, outra prospectiva é realçada na localização (LOC) do cluster, visto como ponto forte para os negócios dos feirantes e percebida na tradição e no reconhecimento pelos consumidores. Tal circunstância representa uma clara demonstração da imagem e legitimidade que o aglomerado já promove para os feirantes participantes, indicando um dos principais ganhos para a competitividade do aglomerado (CA) e desenvolvimento das empresas (DE).

Além disso, as instalações empresariais em aglomerado, por intermédio da colaboração (COL) e dos relacionamentos interorganizacionais (RIOS), proporcionam benefícios de aprendizagem coletiva, economia e barganha nas compras compartilhadas, ampliação das oportunidades de negócios e de mercado, aumento na variedade de produtos e na especialização das vendas, consignação de produtos, bem como redução de custos nas transações, atrelada ao aumento da confiança (PORTER, 1998, 1989; MARSHALL, 1996; KWASNICKA; ZACCARELLI, 2006; ZACCARELLI el al., 2008; BALESTRIN; VERSCHOORE, 2008; SILVA, 2016).

É salutar destacar a relevância social e econômica proveniente da reestruturação produtiva decorrente da formação de novos arranjos organizacionais, em especial, os clusters planejados de pequenas empresas, como o Mercado Municipal Maria Virgínia Leite Franco, em Aracajú/SE. Esses novos arranjos são concebidos como um caminho admissivel para o desenvolvimento de pequenos negócios, uma vez que lhes possibilita melhores condições para superarem as barreiras associadas ao seu tamanho e serem competitivas no mercado. As alianças que se formam nesse tipo de aglomerado empresarial potencializam as trocas de competências, conhecimentos e habilidades (ZACCARELLI et al., 2008), além de promoverem as parcerias e ajudas mútuas. Ademais, aspectos relacionados à cooperação contribuem para a qualidade de vida dos indivíduos participantes dos clusters (ESTIVALETE et al., 2012).

Como principal contribuição desse estudo, constata-se que a causalidade dos relacionamentos cooperativos, competitivos e coopetitivos em clusters varejistas planejados compostos por pequenos 
feirantes são provenientes dos próprios atores, ou seja, é uma ação humana, para os pequenos manteremse no mercado e não uma estratégica, corroborando com os estudos de Silva (2016) e Panda (2017). Além disso, a contribuição gerencial da pesquisa está na evolução dos estudos acerca da coopetição (CZAKON et al., 2014; PANDA, 2017), em formatos organizacionais com equilíbrio da cooperação e da concorrência na dinâmica da coopetição, os clusters varejistas planejados.

Os resultados desse estudo são subsídios para a ascensão das pesquisas acerca da cooperação, competição e coopetição em relação aos novos formatos organizacionais que, neste caso, são os clusters varejistas planejados em cidades de pequeno porte. Para isso, algumas novas pesquisas são propostas: a) uma possível análise confirmatória desse estudo; b) análise multigrupo entre os diversos segmentos do cluster para comparar fatores; e c) a replicação do modelo em aglomerações de varejo não planejadas.

\section{REFERÊNCIAS}

AGUIAR, H. S.; PEREIRA, C. E. C.; DONAIRE, D.; NASCIMENTO, P. T. S. Análise da competitividade de clusters de negócios de varejo: ajuste de métricas através de uma aplicação no cluster varejista de moda do Bom Retiro. Revista de Gestão, São Paulo, n. 24, p. 122-133, 2017.

BALESTRIN, A.; VERSCHOORE, J. R.; REYES JUNIOR, E. O campo de estudo sobre redes de cooperação interorganizacional no Brasil. Revista de Administração Contemporânea, Curitiba, v. 14, n. 3, p. 458477, 2010.

BALESTRIN, A.; VERSCHOORE, J. Redes de cooperação empresarial: estratégia de gestão na nova economia. 2. ed. Porto Alegre: Bookman, 2016. 291 p.

BALESTRIN, A.; VERSCHOORE, J. Fatores relevantes para o estabelecimento de redes de cooperação entre empresas do Rio Grande do Sul. Revista de Administração Contemporânea, Curitiba, v. 12, n. 4, p. 1043-1069, 2008.

BELFIORE, P. P.; FÁVERO, L. P. L.; ANGELO, C. F. Análise multivariada para avaliação do comportamento de grupos supermercadistas brasileiros. Administração em Diálogo, São Paulo, n. 7, p. 53-75, 2005.

BENGTSSON, M.; KOCK, S. Coopetition in Business Network: to cooperate and compete simultaneously. Industrial Marketing Management, [s.I.], v. 29, n. 5, p. 411-426, 2000.

BERTOSSO, H. EBERT, P. N. P. LAIMER, C. G. O Papel da Confiança nas Redes Interorganizacionais Evidência Empírica em Rede de Fornecedores. Revista Unijuí v. 15, n. 41, p. 303-334, 2017. 
CORRAR, L. J.; PAULO, D.; DIAS FILHO, J. M. Análise multivariada para cursos de administração, ciências contábeis e economia. 2. ed. [S.I.]: Atlas, 2009. 568 p.

CZAKON, W., MUCHA-KUS, K. ROGALSKI, M. Coopetition research landscape - a systematicliterature review 1997-2010. Journal of Economics and Management, Katowice. v. 17, p. 122-150, 2014.

DANA, L.; GRANATA, J. Evolution de La coopétition dans um cluster: le cas de Waipara dans le secteur du vin. Journal of Small Business \& Entrepreneurship, Montpellier, v. 26, n. 4, p. 429-442, 2013.

ESTIVALETE, V. F. B.; GOMES, T. C.; CAMPOS, S. A. P.; RIBAS, F. L.; SOUZA, G. Motivos, Benefícios e Aprendizagem: Um estudo envolvendo Relacionamentos Interorganizacionais no Terceiro Setor. Revista Brasileira de Administração Científica, Aquidabã, v.3, n. 3, p. 201-215, 2012.

FERREIRA, M. P.; STOROPOLI, J. E.; SERRA, F. R. Two decades of research on strategic alliances: analysis of citations, co-citations and themes researched. Revista de Administração Contemporânea, v. 18, edição especial, p. 109-133, 2014.

GERAUDEL, M. SALVETAT, D. "What are the antecedents of coopetition? An explanation in terms of centrality and personality traits". European Business Review, v. 26, n. 1, pp. 23-42, 2014.

GILBERT, D. Retail Marketing Management. 2. ed. [S.I.]: Financial Times Prentice Hall, 2003. 457 p.

HAIR JUNIOR, J. F.; BLACK, W. C.; BABIN, B. J.; ANDERSON, R. E.; TATHAM, R. L. Análise multivariada de dados. 6. ed. Porto Alegre: Bookman, 2009. 688 p.

HITT, M. A.; IRELAND, R. D; HOSKISSON, R. E. Administração Estratégica: competitividade e globalização. 2. ed. São Paulo: Cengage Learning, 2011. 442 p.

KLEIN, L. L.; ALVES, J. N.; PEREIRA, B. A. D. Quem devemos ler? Principais temas de pesquisa sobre redes interorganizacionais. Revista Organizações em Contexto, v. 11, n. 21, p. 161-184, 2015.

KWASNICKA, E. L.; ZACCARELLI, S. B. A competitividade e racionalidade de um cluster industrial. Revista de Administração da Unimep, São Paulo, v. 4, n. 2, p. 1-17, 2006

LIMA, M. I. R.; GEHLEN, L. Co-opetição em uma Rede de Cooperação. Revista Gestão e Desenvolvimento, v. 3, n. 2, 2006.

LUO, X.; SLOTEGRAAF, R. J.; PAN, X. Cross-Functional "Coopetition": The Simultaneous Role of Cooperation and Competition within Firms. Journal of Marketing, [s.I.], v. 70, p. 67-80, 2006.

MARSHALL, A. Princípios de economia: tratado introdutório. São Paulo: Nova cultural, 1996. (Os economistas, v. 1). 368 p. 
MONTICELLI, J. M.; Competição, cooperação e coopetição: simetrias e discrepâncias na indústria vitivinícola do RS. Revista de Administração da UNIMEP, [s.l.], v. 13, n. 2, p. 1-25, 2015.

MORAIS, R. T. R.; ZDANOWICZ, J. E. A empresa em rede: um espaço alargado para a reorganização do trabalho. Revista Gestão e Desenvolvimento, v. 10, n. 1, p. 9-16, 2013.

NALEBUFF, B. J.; BRANDENBURGER, A. M. Co-opetição: um conceito revolucionário que combina competição com cooperação [...]. Rio de Janeiro: Rocco, 1996. 308 p.

PADULA, G.; DAGNINO, G. B. Untangling the Rise of Coopetition: the instrusion of competition in a cooperative game structure. Int. Studies of Mgt. e Org., [s.I.], v. 37, n. 2, p. 32-52, 2007.

PANDA, D. K. Coevolution and coexistence of cooperation and competition in interorganizational collaboration Evidences from Indian management consulting industry. Journal of Global Operations and Strategic Sourcing. v. 10, n. 1, p.18-41, 2017.

PORTER, M. E. Clusters and the New Economics of Competition. Harvard Business Review, Boston, p. 77-90, 1998.

PORTER, M. A Vantagem competitiva das Nações. Trad. Waltensir Dutra. Rio de Janeiro: Campus, 1989. $897 \mathrm{p}$.

PORTER, Michael E. Competição - Estratégias Competitivas Essenciais. Tradução Afonso Celso da Cunha Serra. Rio de Janeiro: Elsevier, 2009. 546 p.

SILVA, R. S. Coopetição em aglomerações comerciais planejadas e não planejadas. 2016. 208 fls. Tese (Doutorado em Administração) - Universidade Municipal de São Caetano do Sul, São Caetano do Sul, 2016.

SIQUEIRA, J. P. L.; GERTH, F. M.; BOAVENTURA, J. M. G. Análise da competitividade dos clusters industriais de calçados de França e Birigui. Revista Gestão Organizacional, São Paulo, v. 4, n. 2, p. 197-216, 2011.

TELLER, C. Shopping Streets versus Shopping Malls: Determinants of Agglomeration Format Attractiveness from the Consumers' Point of View. International Review of Retail, Distribution and Consumer Research, Stirling, v. 18, n. 4, p. 381-403, 2008.

TELLES, R. Clusters e redes de negócios. IESDE Brasil S.A., Curitiba, 2008. 216 p.

ZACCARELLI, S. B.; TELLES, R.; SIQUEIRA, J. P. L.; BOAVENTURA, J. M. G.; DONAIRE, D. Clusters e redes de negócios: uma nova visão para a gestão dos negócios. São Paulo: Atlas, 2008. 228 p. 